\title{
How safe are elective craniotomies in elderly patients in neurosurgery today? A prospective cohort study of 1452 consecutive cases
}

\author{
*Ralph T. Schär, MD, ${ }^{1}$ Shpend Tashi, MMed, ${ }^{1}$ Mattia Branca, PhD, ${ }^{2}$ Nicole Söll, ${ }^{1}$ \\ Debora Cipriani, MD, ${ }^{1,3}$ Christa Schwarz, MD, ${ }^{1}$ Claudio Pollo, MD, ${ }^{1}$ Philippe Schucht, MD, \\ Christian T. Ulrich, MD, ${ }^{1}$ Jürgen Beck, MD, ${ }^{1,3}$ Werner J. Z'Graggen, MD, ${ }^{1}$ and Andreas Raabe, MD1
}

${ }^{1}$ Department of Neurosurgery, Inselspital, Bern University Hospital, University of Bern; ${ }^{2}$ Clinical Trials Unit Bern, University of Bern, Switzerland; and ' ${ }^{3}$ epartment of Neurosurgery, Medical Center, University of Freiburg, Freiburg im Breisgau, Germany

OBJECTIVE With global aging, elective craniotomies are increasingly being performed in elderly patients. There is a paucity of prospective studies evaluating the impact of these procedures on the geriatric population. The goal of this study was to assess the safety of elective craniotomies for elderly patients in modern neurosurgery.

METHODS For this cohort study, adult patients, who underwent elective craniotomies between November 1, 2011, and October 31, 2018, were allocated to 3 age groups (group 1, < 65 years [ $n=1008$ ], group 2, $\geq 65$ to $<75$ [ $n=315$ ], and group $3, \geq 75$ [ $n=129]$ ). Primary outcome was the 30-day mortality after craniotomy. Secondary outcomes included rate of delayed extubation (> 1 hour), need for emergency head CT scan and reoperation within 48 hours after surgery, length of postoperative intensive or intermediate care unit stay, hospital length of stay (LOS), and rate of discharge to home. Adjustment for American Society of Anesthesiologists Physical Status (ASA PS) class, estimated blood loss, and duration of surgery were analyzed as a comparison using multiple logistic regression. For significant differences a post hoc analysis was performed.

RESULTS In total, 1452 patients (mean age $55.4 \pm 14.7$ years) were included. The overall mortality rate was $0.55 \%$ ( $n$ $=8$ ), with no significant differences between groups (group 1: 0.5\% [95\% binominal Cl 0.2\%, 1.2\%]; group 2: $0.3 \%$ [ $95 \%$ binominal $\mathrm{Cl} 0.0 \%, 1.7 \%$ ]; group 3: $1.6 \%$ [95\% binominal $\mathrm{Cl} 0.2 \%, 5.5 \%]$ ). Deceased patients had a significantly higher ASA PS class ( $2.88 \pm 0.35$ vs $2.42 \pm 0.62$; difference 0.46 [95\% $\mathrm{Cl} 0.03,0.89] ; p=0.036$ ) and increased estimated blood loss (1444 $\pm 1973 \mathrm{ml}$ vs $436 \pm 545 \mathrm{ml}[95 \% \mathrm{Cl} 618,1398] ; p<0.001)$. Significant differences were found in the rate of postoperative head CT scans (group 1: $6.65 \%$ [ $n=67$ ], group 2: $7.30 \%$ [ $n=23$ ], group 3: $15.50 \%$ [ $n=20$ ]; $p=0.006$ ), LOS (group 1: median 5 days [IQR 4; 7 days], group 2: 5 days [IQR 4; 7 days], and group 3: 7 days [5; 9 days]; $p=0.001$ ), and rate of discharge to home (group 1: $79.0 \%$ [ $=796$ ], group 2: $72.0 \%$ [ $=227$ ], and group 3: $44.2 \%$ [ $=57$ ]; $p<0.001$ ).

CONCLUSIONS Mortality following elective craniotomy was low in all age groups. Today, elective craniotomy for wellselected patients is safe, and for elderly patients, too. Elderly patients are more dependent on discharge to other hospitals and postacute care facilities after elective craniotomy.

Clinical trial registration no.: NCT01987648 (clinicaltrials.gov).

https://thejns.org/doi/abs/10.3171/2020.2.JNS193460

KEYWORDS elderly; elective craniotomy; postoperative complications; mortality; oncology

$\mathrm{D}$ EMOGRAPHIC transition, mainly due to increasing life expectancy, has led to global population aging. ${ }^{1}$ According to its latest report in 2017, the United Nations estimated the population aged 60 years or older to number 962 million. Moreover, the number of octogenarians is expected to triple globally by 2050 , ascending from 137 million to 425 million. Although twothirds of the elderly population live in developing regions, population aging is most advanced in Europe and in North America. ${ }^{2}$ Consequently, the increase of the proportion of

ABBREVIATIONS ASA = American Society of Anesthesiologists; EBL = estimated blood loss; GCS = Glasgow Coma Scale; ICU = intensive care unit; IMCU = intermediate care unit; LOS = length of stay; PAC = postacute care; PS = Physical Status.

SUBMITTED December 20, 2019. ACCEPTED February 5, 2020.

INCLUDE WHEN CITING Published online April 24, 2020; DOI: 10.3171/2020.2.JNS193460.

* R.T.S. and S.T. contributed equally to this work, and W.J.Z. and A.R. share senior authorship. 
elderly people in the population has led to a higher demand of older and frailer patients seeking or requiring surgical procedures. ${ }^{3,4}$ Elderly patients have more comorbidities and a higher disease burden, which make them more susceptible to surgical complications. ${ }^{5}$ In the United States up to $20 \%$ of the population older than 65 years of age are estimated to be afflicted by frailty. ${ }^{6}$ These patients are especially vulnerable for adverse health outcomes, leading to disability, dependency, need for long-term care, and mortality.

Mortality rates are one of the most frequently assessed quality measures, especially in complex surgical subspecialties such as neurosurgery, and much effort has gone into understanding and decreasing these rates. ${ }^{8,9}$ Large studies from the National Surgical Quality Improvement Program (NSQIP) on craniotomy for meningioma resection in the elderly have demonstrated that advanced age is an independent predictor for poorer outcome and increased mortality. ${ }^{10,11}$ It is of great interest to comprehend and predict the present and future impact of the growing proportion of elderly patients on surgical outcomes. ${ }^{3,12,13}$ It has been shown in other surgical subspecialties that advanced age is an important risk factor for postoperative complications and increased mortality. ${ }^{14,15}$ We thus hypothesized that there is an increased incidence of postoperative 30-day mortality among elderly patients after elective craniotomy procedures. This in turn has to be considered when selecting the best management option for this patient population.

To the best of our knowledge, no study has yet comprehensively and prospectively analyzed short-term outcomes and mortality rates in the elderly neurosurgical population following elective craniotomy. The objective of the present study was to evaluate the safety and short-term outcome after elective craniotomy procedures for elderly patients in a prospective series.

\section{Methods \\ Data}

Data from our institutional database on elective craniotomies were used to conduct a prospective cohort study on adult patients consecutively operated on at our institution. The electronic database-compliant with good clinical practice standards-contains prospectively collected clinical, surgical, and perioperative information of all adult patients who undergo elective craniotomy procedures. The database was registered at ClinicalTrials.gov (NCT01987648) and approved by the institutional review board and the local ethics committee (Kantonale Ethikkommission Bern, Switzerland). Written general consent was obtained from all patients included in the database.

\section{Patients}

The patient cohort comprised all eligible adult patients who underwent an elective craniotomy procedure during a period of 7 years, between November 1,2011, and October 31,2018 , at our institution and who gave written general consent for study inclusion. A total of 7427 patients undergoing cranial procedures at our hospital were prospectively screened for study inclusion. Patients younger than
18 years of age, with a history of craniotomy, procedures for underlying infections, biopsy-only cases, procedures not involving a craniotomy (e.g., burr hole-only cases, transsphenoidal approaches), awake surgeries, or nonelective craniotomies (e.g., for traumatic brain injury) were excluded. In total, 1452 patients were included for final data analysis. Figure 1 presents a flow diagram of all patients screened and excluded.

\section{Variables}

Patients were divided into 3 discrete age groups: younger than 65 years (group 1), 65 to 74 years (group 2), and 75 years or older (group 3). For the purpose of this study the latter group served as the definition for elderly patients.

Database variables were predefined in a case report form and included patient demographics, American Society of Anesthesiologists Physical Status (ASA PS) class, preoperative medication and laboratory results, entity and location of primary cranial lesion, mode of anesthesia, duration of surgery, estimated blood loss (EBL), time from skin closure to extubation, need for emergency head CT (performed for unexpected neurological findings), or reoperation within 48 hours after surgery. All time points of perioperative events (e.g., skin incision, skin closure, extubation, transfer to intermediate or intensive care unit [IMCU/ICU], patient discharge) and discharge destination were recorded and included in the database. As we have previously reported, failure to extubate within 1 hour after skin closure was considered delayed extubation. ${ }^{16}$ Surgical and anesthesia reports of all included patients and histopathological reports, where applicable, were reviewed.

The primary outcome measure was mortality at 30 days after elective craniotomy. Secondary outcomes were the rate of emergency head CT scans and reoperations within 48 hours after the index surgery, rate of delayed extubation, length of postoperative IMCU or ICU stay, hospital length of stay (LOS), and rate of discharge to home directly.

\section{Institutional Standard Operating Procedures for Elective Craniotomies}

All cranial surgeries were performed by board-certified neurosurgeons. For all supratentorial lesions, intraoperative neuronavigation was used for tailoring the craniotomy. Patients with suspected high-grade gliomas received 5-aminolevulinic acid preoperatively, allowing for fluorescence-guided tumor resection. Multimodal intraoperative neuromonitoring was used for eloquent tumors in the proximity of presumed motor, speech, or vision function. Intraoperative ultrasound and intraoperative MRI for verification of extent of tumor resection were used at the surgeon's discretion. Immediate extubation in the operating room was routinely foreseen for all elective craniotomy procedures. Postoperative clinical monitoring was performed at a dedicated neurosurgical IMCU or, rarely, at an ICU until the next day. Patients with uneventful postoperative surveillance were then discharged to the wards. Postoperative head CT scans were only ordered for unexpected neurological findings or acute worsening. Microscope-based indocyanine green and sodium fluores- 
cein videoangiography were routinely used during aneurysm surgery for real-time information regarding vessel patency. ${ }^{17,18}$

\section{Statistical Analysis}

Descriptive analysis was performed using frequencies and percentages for categorical variables and mean $( \pm$ $\mathrm{SD}$ ) or median (IQR) for continuous variables. Chi-square tests or Fisher exact tests and ANOVA were used to compare categorical and continuous variables, respectively. The analysis was based on the comparison among the 3 age groups defined: < 65 years (group 1), 65-74 years (group 2), and $\geq 75$ years (group 3). Descriptive analysis was performed for baseline characteristics, surgical, postoperative care, and patient transfer data. Binary outcome measures were analyzed by Fisher exact test or chi-square test (depending on the frequencies of the outcomes), while the Kruskal-Wallis test was used to account for large values for continuous outcomes, such as LOS. Adjustment for ASA class, EBL, and duration of surgery was also tested as a comparison using multiple logistic regression and quantile regression to account for potential selection bias. For significant differences a post hoc analysis was performed. A p value $<0.05$ was considered statistically significant for all analyses, and the Bonferroni correction was applied for post hoc analysis. Statistical analysis was performed using Stata 15 (StataCorp LLC).

\section{Results \\ Demographics and Patient Characteristics}

Of the total 1452 patients included for final analysis, $44 \%$ were men and $56 \%$ were women, and the overall mean age was $55.4 \pm 14.7$ years. Group 1 ( $<65$ years $)$ comprised 1008 patients, group 2 (65-74 years) 315, and group 3 ( $\geq 75$ years [range 75-89 years]) 129. The most common indication for elective craniotomy for all age groups was meningioma. The incidence of this entity increased steadily from $28 \%$ in group 1, to $33 \%$ in group 2, and to $44 \%$ in group 3 . Conversely, vascular lesions were operated on less frequently with increasing age, representing the main diagnosis for craniotomy in $17 \%$ of patients younger than 65 years, in $10 \%$ of patients aged 65-74 years, and in merely $4 \%$ of patients aged 75 or older. Demographic and clinical data of patients are presented in Table 1 .

\section{Primary Outcome}

In total, 8 patients ( 5 women, 3 men; mean age 59.4 \pm 16.6 years) of the entire cohort of 1452 patients died within 30 days after elective craniotomy, corresponding to an overall mortality rate of $0.55 \%$ over the recruitment period of 7 years. Mortality rates showed no statistically significant differences between the 3 age groups (Table 2). Table 3 summarizes the 8 cases with fatal outcome with respect to patient demographics, primary diagnosis, and cause of death.

The group of deceased patients $(n=8)$ had a statistically significant higher mean ASA class $(2.88 \pm 0.35$ vs $2.42 \pm 0.62$; difference 0.46 [95\% CI 0.03, 0.89]; $\mathrm{p}=0.036$ ) and higher EBL $(1444 \pm 1973 \mathrm{ml}$ vs $436 \pm 545 \mathrm{ml}$; differ-

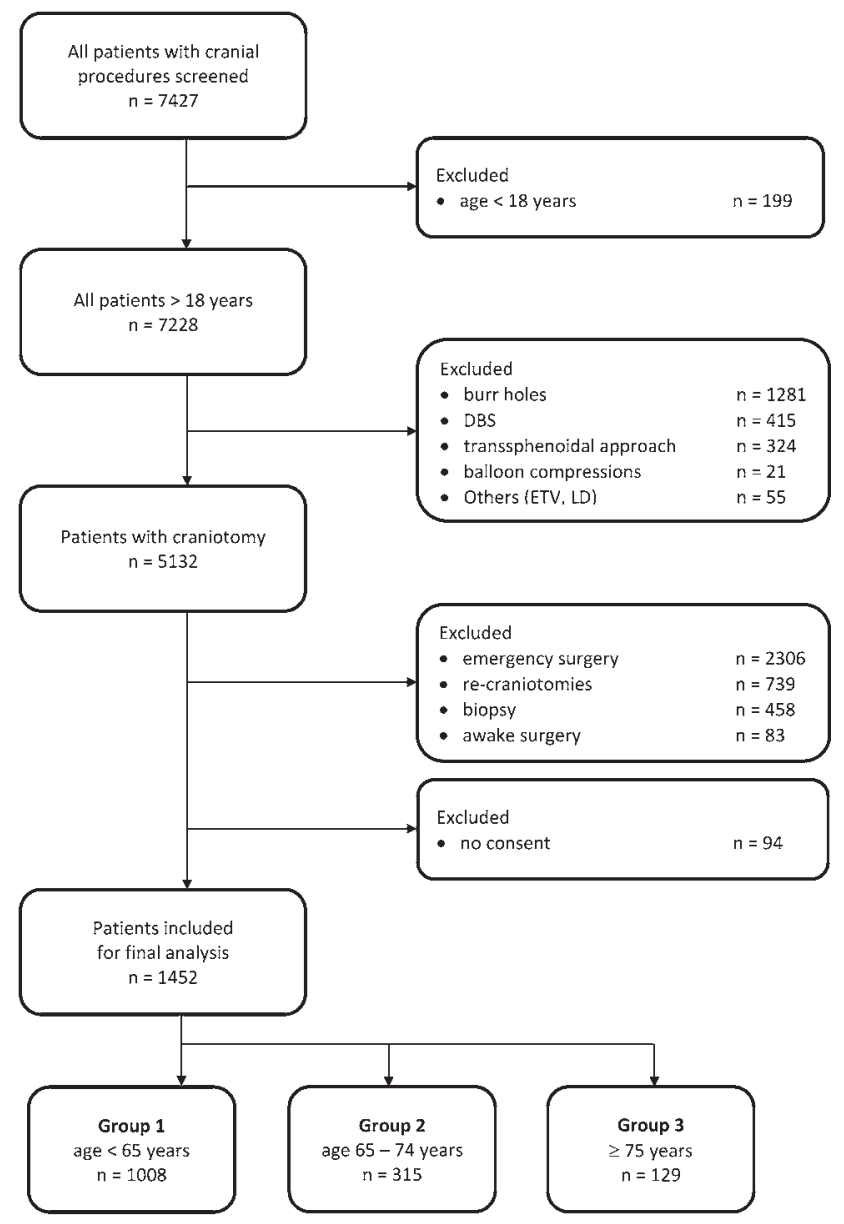

FIG. 1. Flow diagram of patients screened for study inclusion. DBS = deep brain stimulation; ETV = endoscopic third ventriculostomy; $L D=$ lumbar drain.

ence 1008 [95\% CI 618, 1398]; $\mathrm{p}<0.001$ ) than the group of surviving patients $(\mathrm{n}=1444)$.

\section{Secondary Outcomes \\ Delayed Extubation}

For 1402 (96.6\%) of 1452 patients, early extubation within 1 hour after skin closure was successful. Correspondingly, in $3.4 \%$ of cases $(n=50)$ early extubation failed. There was no significant difference with regard to rate of delayed extubation between the 3 age groups (Table 2).

\section{Emergency Postoperative Head CT Scans}

One hundred ten patients (7.6\%) were sent for emergency head CT scans within 48 hours after skin closure due to unexpected neurological findings or acute worsening. Significantly more CT scans were performed for elderly patients than for younger patients (group 1: 67/1008 [6.65\%]; group 2: 23/315 [7.30\%]; and group 3: 20/129 [15.50\%]; unadjusted $\mathrm{p}=0.002$, adjusted $\mathrm{p}=0.006$ ). Post hoc analysis showed both a significantly higher rate of CT scans in the comparison of group 1 and group 3 (unadjusted $p=0.001$, adjusted $p=0.001$ ) and between group 2 and group 3 (un- 
TABLE 1. Patient demographic and clinical characteristics stratified by age group

\begin{tabular}{|c|c|c|c|c|c|}
\hline \multirow[b]{2}{*}{ Characteristic } & \multirow[b]{2}{*}{ All Patients } & \multicolumn{3}{|c|}{ Age Groups } & \multirow[b]{2}{*}{ p Value } \\
\hline & & $<65$ Yrs & $65-74$ Yrs & $\geq 75$ Yrs & \\
\hline No. of patients & 1452 & 1008 & 315 & 129 & \\
\hline Age (yrs) & $55.44 \pm 14.71$ & $48.32 \pm 11.55$ & $68.84 \pm 2.73$ & $78.37 \pm 3.81$ & \\
\hline Male & $632(43.53)$ & $433(42.96)$ & $143(45.40)$ & $56(43.41)$ & 0.747 \\
\hline \multicolumn{6}{|l|}{ ASA PS class } \\
\hline 1 & 64 (4.41) & $58(5.75)$ & $5(1.59)$ & $1(0.78)$ & 0.001 \\
\hline 2 & $748(51.52)$ & $586(58.13)$ & $119(37.78)$ & $43(33.33)$ & $<0.001$ \\
\hline 3 & $607(41.80)$ & $349(34.62)$ & $180(57.14)$ & $78(60.47)$ & $<0.001$ \\
\hline 4 & $32(2.20)$ & $14(1.39)$ & $11(3.49)$ & $7(5.43)$ & 0.003 \\
\hline 5 & $1(0.07)$ & $1(0.10)$ & $0(0)$ & $0(0)$ & 0.802 \\
\hline \multicolumn{6}{|l|}{ Primary diagnosis } \\
\hline Meningioma & $440(30.30)$ & $279(27.68)$ & $104(33.02)$ & $57(44.19)$ & $<0.001$ \\
\hline High-grade glioma & 209 (14.39) & $118(11.71)$ & $63(20.00)$ & $28(21.71)$ & $<0.001$ \\
\hline Other primary brain tumor & $229(15.77)$ & $196(19.44)$ & $25(7.94)$ & $8(6.20)$ & $<0.001$ \\
\hline Metastasis & $196(13.50)$ & $112(11.11)$ & $62(19.68)$ & $22(17.05)$ & $<0.001$ \\
\hline Vascular & $208(14.33)$ & $172(17.06)$ & $31(9.84)$ & $5(3.88)$ & $<0.001$ \\
\hline Others & $170(11.71)$ & $131(13.00)$ & $30(9.52)$ & $9(6.98)$ & 0.053 \\
\hline $\mathrm{EBL}(\mathrm{ml})$ & $441 \pm 566$ & $422 \pm 522$ & $498 \pm 716$ & $449 \pm 459$ & 0.118 \\
\hline Duration of op (hrs) & $4.31 \pm 1.85$ & $4.40 \pm 1.90$ & $4.21 \pm 1.79$ & $3.89 \pm 1.45$ & 0.007 \\
\hline
\end{tabular}

Values are presented as the number (\%) of patients or as the mean $\pm \mathrm{SD}$.

adjusted $\mathrm{p}=0.012$, adjusted $\mathrm{p}=0.005)$ (Fig. 2A). Overall, the 3 most frequent reasons for ordering a postoperative emergency head CT scan were the development of a new motor deficit (27\%), deterioration on the Glasgow Coma Scale (GCS) (25\%), and postoperative seizure (13\%). Further details and patient characteristics regarding postoperative head CT scans are listed in Table 2.

Urgent Reoperation Within 48 Hours and Length of Postoperative IMCU or ICU Stay

The rate of urgent neurosurgical reoperations within 48 hours after skin closure and of postoperative stay at the IMCU or ICU showed no significant differences between the 3 age groups (Table 2).

\section{Hospital LOS}

The median LOS after elective craniotomy for all patients was 5 days (IQR 4; 7 days). Statistical comparison of the 3 age groups revealed a significantly longer LOS for elderly patients (group 1: median 5 days [IQR 4; 7 days], group 2: 5 days [IQR 4; 7 days], and group 3: 7 days [IQR 5 ; 9 days]; unadjusted $\mathrm{p}<0.001$, adjusted $\mathrm{p}=0.001$ ). The mean LOS in group 1 was significantly shorter than that in group 3, as observed in the post hoc analysis (unadjusted and adjusted $\mathrm{p}<0.001$ ). This was also true for post hoc comparison of group 2 and group 3 (unadjusted $p=0.003$, adjusted $\mathrm{p}<0.001$ ) (Fig. 2B).

\section{Hospital Discharge}

Of all the postoperative patients, 1080 (74.4\%) were fit for discharge to home directly. The remaining 372 patients $(25.6 \%)$ were discharged to other regional hospitals or postacute care (PAC) facilities, such as rehabilitation clinics or nursing homes. While $79.0 \%$ of patients in group 1 and $72.0 \%$ of patients in group 2 were discharged to home directly, this was the case in only $44.2 \%$ of patients in group $3(\mathrm{p}<0.001$, Table 2$)$. The higher rate of discharge to home in group 1 was statistically significant in comparison to both group $2(\mathrm{p}=0.013)$ and group $3(\mathrm{p}$ $<0.001$ ) More details regarding discharge destination are presented in Fig. 2C-E.

\section{Discussion}

\section{Mortality After Elective Craniotomy and the Quest for Adequate Prediction Models}

The overall 30-day mortality rate after elective craniotomy across all age groups comprising 1452 patients over 7 years was $0.55 \%$. This rate is well in line with previous retrospective reports on surgical mortality in cranial neurosurgery, ranging from $0.2 \%$ to $12 \% .^{10,19-23}$ Importantly, in our study older age ( $\geq 75$ years) did not influence the risk of fatal outcome after cranial surgery. For that matter, the mean age of the 8 patients who died within 30 days of craniotomy was 59 years, and only 2 patients were older than 75 years. Of note, 2 patients died 12 and 20 days after surgery due to progression of their underlying malignant brain tumor (glioblastoma and brain metastasis from lung cancer, respectively). As such, only 6 of 1452 patients died due to direct intra- or postoperative events, essentially lowering surgical mortality to $0.41 \%$. It has recently been concluded that longer operations in neurosurgery are potential predictors of 30-day mortality. ${ }^{24}$ As shown in Table 1 , in our series elderly patients (group 3 ) had significantly 


\begin{tabular}{|c|c|c|c|c|c|c|}
\hline \multirow[b]{2}{*}{ Outcome Measure } & \multirow[b]{2}{*}{ All Patients $(n=1452)$} & \multicolumn{3}{|c|}{ Age Groups } & \multirow[b]{2}{*}{$p$ Value } & \multirow{2}{*}{$\begin{array}{l}\text { Adjusted } \\
\text { p Value }\end{array}$} \\
\hline & & $<65$ Yrs $(n=1008)$ & $65-74$ Yrs $(n=315)$ & $\geq 75$ Yrs (n = 129) & & \\
\hline \multicolumn{7}{|l|}{ Primary outcome } \\
\hline Patient death (mortality rate) & $8(0.55)$ & $5(0.50)$ & $1(0.32)$ & $2(1.55)$ & 0.257 & 0.633 \\
\hline \multicolumn{7}{|l|}{ Secondary outcomes } \\
\hline Delayed extubation (>1 hr) (yes) & $50(3.44)$ & $30(2.98)$ & $12(3.81)$ & $8(6.20)$ & 0.154 & 0.133 \\
\hline Emergency head CT & $110(7.58)$ & $67(6.65)$ & $23(7.30)$ & $20(15.50)$ & 0.002 & 0.006 \\
\hline \multicolumn{7}{|l|}{ Reason for emergency head CT } \\
\hline Postop seizure & $14(12.73)$ & $9(13.43)$ & $2(8.70)$ & $3(15.00)$ & 0.850 & \\
\hline GCS score deterioration & $27(24.55)$ & $16(23.88)$ & $5(21.74)$ & $6(30.00)$ & 0.819 & \\
\hline New motor deficit & $30(27.27)$ & $17(25.37)$ & $10(43.48)$ & $3(15.00)$ & 0.100 & \\
\hline New cranial nerve palsy & $7(6.36)$ & $5(7.46)$ & $1(4.35)$ & $1(5.00)$ & 1.000 & \\
\hline New speech impairment & $7(6.36)$ & $2(2.99)$ & $3(13.04)$ & $2(10.00)$ & 0.101 & \\
\hline New visual impairment & $5(4.55)$ & $4(5.97)$ & $0(0)$ & $1(5.00)$ & 0.676 & \\
\hline Other & $20(18.18)$ & $14(20.90)$ & $2(8.70)$ & $4(20.00)$ & 0.446 & \\
\hline Reoperation & $20(1.38)$ & $15(1.49)$ & $2(0.63)$ & $3(2.33)$ & 0.329 & 0.941 \\
\hline \multicolumn{7}{|l|}{ Reason for reoperation } \\
\hline Postoperative ICH & $9(45)$ & $6(40)$ & $1(50)$ & $2(67)$ & & \\
\hline Intracranial swelling & $3(15)$ & $3(20)$ & $0(0)$ & $0(0)$ & & \\
\hline Hydrocephalus & $2(10)$ & $2(13)$ & $0(0)$ & $0(0)$ & & \\
\hline Other & $6(30)$ & $4(27)$ & $1(50)$ & $1(33)$ & & \\
\hline \multicolumn{7}{|l|}{ Surgical procedure } \\
\hline Recraniotomy & $3(15)$ & $3(20)$ & $0(0)$ & $0(0)$ & & \\
\hline Decompressive hemicraniectomy & $9(45)$ & $6(40)$ & $1(50)$ & $2(67)$ & & \\
\hline EVD & $7(35)$ & $5(33)$ & $1(50)$ & $1(33)$ & & \\
\hline Other & $1(5)$ & $1(7)$ & $0(0)$ & $0(0)$ & & \\
\hline Length of IMCU/ICU stay, hrs & $20.2(18.5 ; 21.7)$ & $20.2(18.4 ; 21.7)$ & $20.4(18.8 ; 21.9)$ & $20.1(18.3 ; 21.6)$ & 0.303 & 0.171 \\
\hline LOS, days & $5(4 ; 7)$ & $5(4 ; 7)$ & $5(4 ; 7)$ & $7(5 ; 9)$ & $<0.001$ & 0.001 \\
\hline \multicolumn{7}{|l|}{ Discharge to } \\
\hline Home directly & $1080(74.38)$ & $796(78.97)$ & $227(72.06)$ & $57(44.19)$ & $<0.001$ & \\
\hline Other hospital & $116(7.99)$ & $53(5.26)$ & $28(8.89)$ & $35(27.13)$ & $<0.001$ & \\
\hline Rehabilitation clinic & $248(17.08)$ & $153(15.18)$ & $59(18.73)$ & $36(27.91)$ & 0.001 & \\
\hline Nursing home & $3(0.21)$ & $2(0.20)$ & $0(0)$ & $1(0.78)$ & 0.262 & \\
\hline Died in hospital & $5(0.34)$ & $4(0.40)$ & $1(0.32)$ & $0(0)$ & 0.766 & \\
\hline
\end{tabular}

$\mathrm{EVD}=$ external ventricular drain; $\mathrm{ICH}=$ intracerebral hemorrhage.

Values are presented as the number (\%) of patients or as the median (IQR).

shorter surgeries than patients in the younger age groups. Naturally, patient selection plays an important role, and this might have contributed to homogeneous mortality rates across the 3 groups.

Quality improvement of neurosurgical procedures and in perioperative care is of greatest interest to enhance patient safety. ${ }^{25}$ In general surgery, a procedural postoperative morbidity index using data from large national registries has been proposed to quantify the severity of postoperative complications and to assess surgical outcomes for specific surgical procedures. ${ }^{26}$ In neurosurgery, many health-assessment metrics are also increasingly being emphasized for the aforementioned reasons. ${ }^{24,27}$ Due to the complexity of cranial neurosurgery paired with the in- trinsically high risk of adverse events, mortality rates are one of the most frequently assessed of these metrics. ${ }^{8,27}$ Other operative risk-stratification models analyzing factors derived from clinical registries and presurgical data possibly associated with intra- and postoperative complications of neurosurgical procedures have so far not been shown to have sufficient reliability to be used as outcome measures. ${ }^{25,28}$ Hence, because of the lack of alternatives, mortality rates still are widely accepted as the most appropriate measure to assess the intrinsic surgical risk of elective craniotomy procedures. For future risk-prediction models, specific neuroanatomical, pathological, and surgical considerations need to be equally considered along with established and validated risk-stratification metrics to 
TABLE 3. Overview of fatal outcomes after elective craniotomy, including pathology and cause of death

\begin{tabular}{|c|c|c|c|c|c|}
\hline $\begin{array}{l}\text { Age } \\
\text { (yrs) }\end{array}$ & Sex & $\begin{array}{l}\text { ASA PS } \\
\text { Class }\end{array}$ & Primary Diagnosis & $\begin{array}{l}\text { Time Deceased } \\
\text { After Op (days) }\end{array}$ & Cause of Death \\
\hline 27 & M & 3 & Glioblastoma & 12 & Progressive intracranial disease \\
\hline 79 & M & 3 & Brain metastasis (lung) & 20 & Progressive systemic disease \\
\hline 65 & $\mathrm{~F}$ & 2 & Olfactory groove meningioma & 3 & Intraop ICA injury \\
\hline 42 & $\mathrm{~F}$ & 3 & Brain metastasis (breast) & 3 & $\begin{array}{l}\text { Postop ischemic stroke w/ global } \\
\text { cerebral ischemia }\end{array}$ \\
\hline 58 & M & 3 & Glioblastoma & 5 & Large postop ischemic stroke \\
\hline 60 & $\mathrm{~F}$ & 3 & Arteriovenous malformation & 8 & Intra- \& postop ICH \\
\hline 64 & $\mathrm{~F}$ & 3 & Brain metastasis (thyroid) & 1 & $\begin{array}{l}\text { Postop thromboembolic event } \\
\text { (pulmonary \& cerebral w/ bilat } \\
\text { MCA occlusion) }\end{array}$ \\
\hline 80 & $\mathrm{~F}$ & 3 & Glioblastoma & 8 & Intra- \& postop ICH \\
\hline
\end{tabular}

$\mathrm{ICA}=$ internal carotid artery; $\mathrm{MCA}=$ middle cerebral artery.

develop more accurate models for neurosurgery. The ASA PS is widely used and has been shown to be a useful riskstratification metric for medical complications and mortality after surgery. ${ }^{29}$ In one study of nearly 2.3 million cases from the NSQIP, ASA class had a strong and independent association with postoperative complications and mortality across procedures. In accordance with these findings, in our cohort higher ASA classes, as well as increased EBL, were significantly associated with 30 -day mortality.

\section{The Elderly Craniotomy Patient}

Apart from surgical mortality, elderly patients also had similar outcomes when compared to the younger age groups in our study with regard to timely extubation (within 1 hour), rate of early reoperation, and length of postoperative monitoring at the IMCU or ICU. However, elderly patients had a significantly higher rate of emergency postoperative head CT scans, longer total LOS, and a lower rate of discharge to home directly. Despite the higher rate of head CT scans, elderly patients did not have a significantly higher rate of early reoperation. The relatively frequent decision to order a head CT scan in this age group might be attributable to the greater challenge of postoperative clinical monitoring of elderly patients as compared to younger patients. In the geriatric surgical population, neurological complications have been reported to be the most common type of complication. ${ }^{30,31}$ Indeed, in our series, GCS score deterioration was more frequently the reason for ordering an early postoperative head CT scan in elderly patients than in younger patients.

Our general findings are in accord with previous studies concluding that advanced age per se should not preclude elective craniotomy for elderly patients, namely for brain tumors, since no significant association with higher postoperative morbidity and mortality rates could be demonstrated. ${ }^{32-35}$ However, these studies either were retrospective case series or focused solely on malignant brain tumors. In addition to rate of mortality, our prospective data highlight the occurrence of early critical postop- erative events and discharge patterns in three distinctive age groups. Fundamentally, elective craniotomy remains a low-risk and safe surgical procedure, even for elderly patients. Accordingly, eligible elderly patients should not be a priori deprived of an elective craniotomy procedure. Needless to say, this requires comprehensive patient counseling and a careful risk-benefit analysis by the treating neurosurgeon and anesthesiologist preoperatively.

\section{Common Factors of Postoperative Complications and Mortality in Elderly Patients}

It has been postulated that patient risk factors outweigh surgical complexity by far when estimating the risk of mortality of a surgical procedure..$^{36}$ Among patient factors, frailty, which affects up to $20 \%$ of the population older than 65 years, has repeatedly been associated with an increased risk of adverse postoperative outcomes. ${ }^{6}$ Apart from frailty, Watt and coworkers identified depressive syndromes and smoking among elderly patients as potentially modifiable prognostic factors for postoperative complications following elective surgery. ${ }^{37}$ The authors conclude that early identification and modification of prognostic patient factors in elderly patients in the preoperative setting play an important role in mitigating the risk of adverse outcomes after elective surgery.

\section{Need for PAC After Elective Craniotomy in Elderly Patients}

Due to their limited physiological reserves and tolerance to adverse events, postoperative recovery is more challenging for the older population, and many elderly patients struggle to regain their independence and return to home directly after surgery.$^{38}$ Although statistically significant in our series, LOS was merely increased by 1 day on average for elderly patients compared with patients younger than 65 years. However, while $79 \%$ of patients in the latter group were discharged to home directly, this was the case in merely $44 \%$ of patients older than 75 years. Correspondingly, $56 \%(\mathrm{n}=72)$ of these elderly patients were discharged to other hospitals $(n=35)$ or PAC facilities (36 

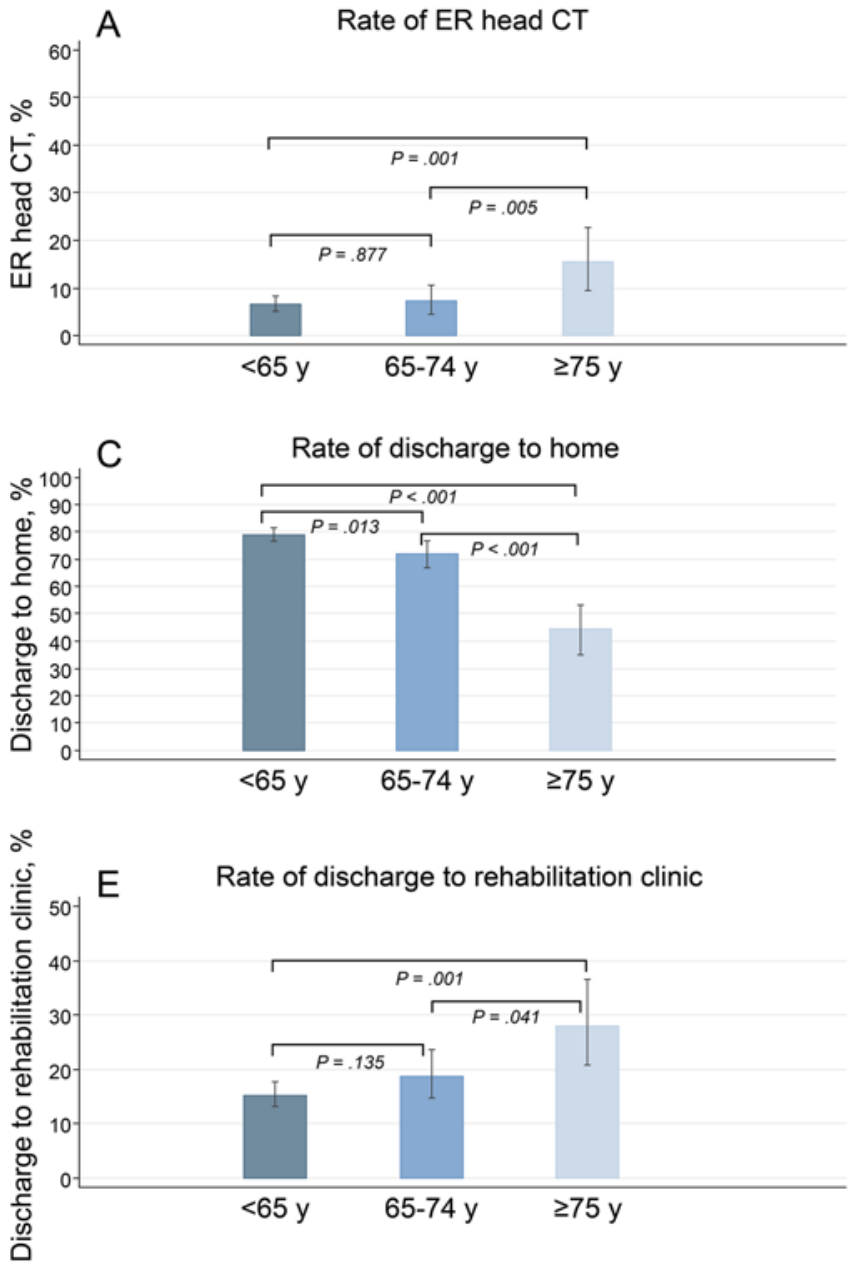

transfers to rehabilitation clinics, 1 transfer to a nursing home) following inpatient hospitalization for an elective craniotomy procedure. These discharge patterns for older patients have been well recognized also in other surgical subspecialties, such as major abdominal surgery. ${ }^{39-41}$ Since quality control in surgery today is also aimed at cost optimization and healthcare reimbursement, stakeholders are keen on mitigating prolonged hospitalization of elderly patients and the need for PAC. However, age alone does not seem to be a significant predictor of increased costs. More importantly, it has recently been shown that frailty, independent of age, leads to increased economic burden in elective surgery. ${ }^{42}$

With the continuing aging of the population, especially in those 65 years of age and older, the specialty of neurosurgery will be increasingly challenged by the associated growth in surgical procedures. Etzioni and colleagues had forecasted a growth in procedure-based work in neurosurgery of $15 \%$ by 2010 and $28 \%$ by 2020 in their study in $2003 .{ }^{3}$ As a consequence, neurosurgery services will have to advance existing standards and cooperate with PAC facilities to ensure mid- and long-term care of elderly patients not fit for discharge to home directly following elective craniotomy. This should be routinely addressed already in the outpatient clinic setting during patient coun-
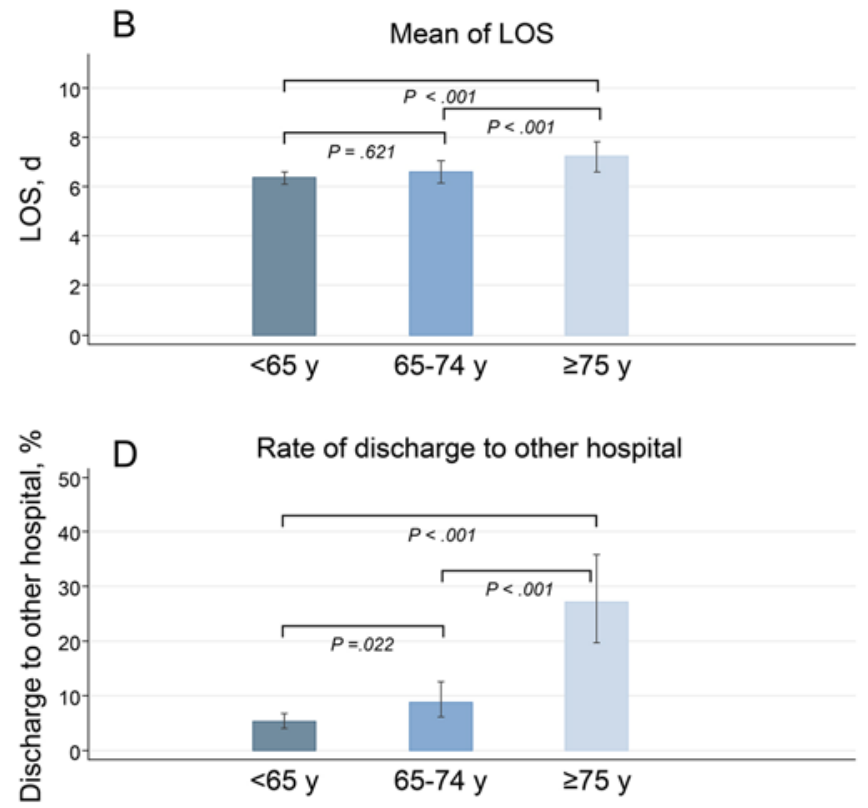

FIG. 2. Comparison of the 3 age groups with post hoc analyses of secondary outcomes with significant results. A: Rate of emergency (ER) head CT scans. B: Mean LOS. C: Rate of discharge to home. D: Rate of discharge to other hospital. E: Rate of discharge to rehabilitation clinic. Figure is available in color online only.

seling, since patients as well as their relatives need to be aware of possible discharge destinations and outcomes.

\section{Limitations}

Our study has several limitations. First, our database on elective craniotomies does not systematically incorporate specific patient comorbidities. Hence, calculation of a comorbidity index, such as the Charlson Comorbidity Index, which in addition to the ASA class might have provided a more substantial insight into preoperative risk assessment, was not feasible. Instead, our study primarily relied on age, the ASA PS class, EBL, and duration of surgery for an overall perioperative risk stratification. Second, we are well aware that our primary outcome of 30-day mortality fails to serve as a comprehensive outcome measure. Although mortality rate is a commonly reported outcome metric, it cannot sufficiently serve as a complete tool for a neurosurgical quality assessment. Of note, the rate of surgical mortality within 30 days is of course also influenced by the mutual decision of the involved surgeons, intensive care specialists, and relatives to withdraw treatment of patients who suffer a severe intra- or postoperative complication with very poor prognosis. Decision-making in these extreme settings may vary substantially depending on the 
religious and cultural background of patients and their family, as well as on regional standards of care, to name a few. Third, naturally there is some inherent selection bias in our study, since elderly patients were judged to be medically fit enough and appropriate surgical candidates. Fourth, due to the low incidence of the primary outcome and the relatively small number of patients in the oldest age group, our study may lack sufficient power, which could challenge the significance of our results.

Finally, since these data have been obtained from a single, tertiary-care university hospital, our results may not be generalizable to the broader neurosurgical community due to differences in perioperative care, technical resources, and patient discharge patterns.

\section{Conclusions}

Overall surgical mortality after elective craniotomy was low and comparable throughout all age groups. Today, elective craniotomy for well-selected patients is safe, importantly, for elderly patients as well. However, elderly neurosurgical patients pose a challenge for immediate postoperative care, and this patient population is more dependent on discharge to other hospitals and PAC facilities. In neurosurgery, preoperative preparation of elderly patients as well as recovery programs after surgery need to be further enhanced to address these discharge patterns.

\section{References}

1. Lutz W, Sanderson W, Scherbov S. The coming acceleration of global population ageing. Nature. 2008;451(7179):716-719.

2. United Nations, Department of Economic and Social Affairs, Population Division. World Population Ageing 2017-Highlights. United Nations; 2017.

3. Etzioni DA, Liu JH, Maggard MA, Ko CY. The aging population and its impact on the surgery workforce. Ann Surg. 2003;238(2):170-177.

4. Partridge JS, Harari D, Dhesi JK. Frailty in the older surgical patient: a review. Age Ageing. 2012;41(2):142-147.

5. Jablonski SG, Urman RD. The growing challenge of the older surgical population. Anesthesiol Clin. 2019;37(3):401-409.

6. Shah R, Attwood K, Arya S, et al. Association of frailty with failure to rescue after low-risk and high-risk inpatient surgery. JAMA Surg. 2018;153(5):e180214.

7. Fried LP, Ferrucci L, Darer J, et al. Untangling the concepts of disability, frailty, and comorbidity: implications for improved targeting and care. J Gerontol A Biol Sci Med Sci. 2004;59(3):255-263.

8. Hammers R, Anzalone S, Sinacore J, Origitano TC. Neurosurgical mortality rates: what variables affect mortality within a single institution and within a national database? $J$ Neurosurg. 2010;112(2):257-264.

9. Houkin K, Baba T, Minamida Y, et al. Quantitative analysis of adverse events in neurosurgery. Neurosurgery. 2009;65(3):587-594.

10. Patil CG, Veeravagu A, Lad SP, Boakye M. Craniotomy for resection of meningioma in the elderly: a multicentre, prospective analysis from the National Surgical Quality Improvement Program. J Neurol Neurosurg Psychiatry. 2010;81(5):502-505.

11. Steinberger J, Bronheim RS, Vempati P, et al. Morbidity and mortality of meningioma resection increases in octogenarians. World Neurosurg. 2018;109:e16-e23.

12. Griffiths R, Beech F, Brown A, et al. Peri-operative care of the elderly 2014: Association of Anaesthetists of Great Britain and Ireland. Anaesthesia. 2014;69(suppl 1):81-98.

13. Hamel MB, Henderson WG, Khuri SF, Daley J. Surgical outcomes for patients aged 80 and older: morbidity and mortality from major noncardiac surgery. J Am Geriatr Soc. 2005;53(3):424-429.

14. Kamiya H, Tanzeem N, Akhyari P, et al. Impact of severe postoperative complications after cardiac surgery on mortality in patients aged over 80 years. Ann Thorac Cardiovasc Surg. 2014;20(5):383-389.

15. Sukharamwala P, Thoens J, Szuchmacher M, et al. Advanced age is a risk factor for post-operative complications and mortality after a pancreaticoduodenectomy: a metaanalysis and systematic review [erratum in: HPB (Oxford). 2012;14(12):877]. HPB (Oxford). 2012;14(10):649-657.

16. Schär RT, Fiechter M, Z'Graggen WJ, et al. No routine postoperative head CT following elective craniotomy-a paradigm shift? PLoS One. 2016;11(4):e0153499.

17. Raabe A, Beck J, Gerlach R, et al. Near-infrared indocyanine green video angiography: a new method for intraoperative assessment of vascular flow. Neurosurgery. 2003;52(1):132-139.

18. Raabe A, Nakaji P, Beck J, et al. Prospective evaluation of surgical microscope-integrated intraoperative near-infrared indocyanine green videoangiography during aneurysm surgery. J Neurosurg. 2005;103(6):982-989.

19. Kalfas IH, Little JR. Postoperative hemorrhage: a survey of 4992 intracranial procedures. Neurosurgery. 1988;23(3):343347.

20. Lassen B, Helseth E, Rønning P, et al. Surgical mortality at 30 days and complications leading to recraniotomy in 2630 consecutive craniotomies for intracranial tumors. Neurosurgery. 2011;68(5):1259-1269.

21. Palmer JD, Sparrow OC, Iannotti F. Postoperative hematoma: a 5-year survey and identification of avoidable risk factors. Neurosurgery. 1994;35(6):1061-1065.

22. Sawaya R, Hammoud M, Schoppa D, et al. Neurosurgical outcomes in a modern series of 400 craniotomies for treatment of parenchymal tumors. Neurosurgery. 1998;42(5):1044-1056.

23. Taylor WA, Thomas NW, Wellings JA, Bell BA. Timing of postoperative intracranial hematoma development and implications for the best use of neurosurgical intensive care. $J$ Neurosurg. 1995;82(1):48-50.

24. Linzey JR, Nadel JL, Wilkinson DA, et al. Validation of the LACE Index (Length of Stay, Acuity of Admission, Comorbidities, Emergency Department Use) in the adult neurosurgical patient population. Neurosurgery. 2020;86(1):E33-E37.

25. Rutkowski M, Sankaran S. Preoperative risk stratification of patient mortality following elective craniotomy; a comparative analysis of prediction algorithms. J Clin Neurosci. 2019;67:24-31.

26. Strasberg SM, Hall BL. Postoperative morbidity index: a quantitative measure of severity of postoperative complications. J Am Coll Surg. 2011;213(5):616-626.

27. Elsamadicy AA, Sergesketter A, Sampson JH, Gottfried ON. Institutional review of mortality in 5434 consecutive neurosurgery patients: are we improving? Neurosurgery. 2018;83(6):1269-1276.

28. Krell RW, Hozain A, Kao LS, Dimick JB. Reliability of risk-adjusted outcomes for profiling hospital surgical quality. JAMA Surg. 2014;149(5):467-474.

29. Hackett NJ, De Oliveira GS, Jain UK, Kim JY. ASA class is a reliable independent predictor of medical complications and mortality following surgery. Int J Surg. 2015;18:184-190.

30. Liu LL, Leung JM. Predicting adverse postoperative outcomes in patients aged 80 years or older. J Am Geriatr Soc. 2000;48(4):405-412.

31. Sieber FE, Barnett SR. Preventing postoperative complications in the elderly. Anesthesiol Clin. 2011;29(1):83-97. 
32. Chaichana KL, Garzon-Muvdi T, Parker S, et al. Supratentorial glioblastoma multiforme: the role of surgical resection versus biopsy among older patients. Ann Surg Oncol. 2011;18(1):239-245.

33. Johans SJ, Garst JR, Burkett DJ, et al. Identification of preoperative and intraoperative risk factors for complications in the elderly undergoing elective craniotomy. World Neurosurg. 2017:107:216-225.

34. Oszvald A, Güresir E, Setzer M, et al. Glioblastoma therapy in the elderly and the importance of the extent of resection regardless of age. J Neurosurg. 2012;116(2):357-364.

35. Seicean A, Seicean S, Schiltz NK, et al. Short-term outcomes of craniotomy for malignant brain tumors in the elderly. Cancer. 2013;119(5):1058-1064.

36. Aust JB, Henderson W, Khuri S, Page CP. The impact of operative complexity on patient risk factors. Ann Surg. 2005;241(6):1024-1028.

37. Watt J, Tricco AC, Talbot-Hamon C, et al. Identifying older adults at risk of harm following elective surgery: a systematic review and meta-analysis. BMC Med. 2018;16(1):2.

38. Li LT, Barden GM, Balentine CJ, et al. Postoperative transitional care needs in the elderly: an outcome of recovery associated with worse long-term survival. Ann Surg. 2015;261(4):695-701.

39. Balentine CJ, Naik AD, Berger DH, et al. Postacute care after major abdominal surgery in elderly patients: intersection of age, functional status, and postoperative complications. JAMA Surg. 2016;151(8):759-766.

40. Balentine CJ, Naik AD, Robinson CN, et al. Association of high-volume hospitals with greater likelihood of discharge to home following colorectal surgery. JAMA Surg. 2014;149(3):244-251.
41. Sacks GD, Lawson EH, Dawes AJ, et al. Which patients require more care after hospital discharge? An analysis of postacute care use among elderly patients undergoing elective surgery. J Am Coll Surg. 2015;220(6):1113-1121.e2.

42. Wilkes JG, Evans JL, Prato BS, et al. Frailty cost: economic impact of frailty in the elective surgical patient. $\mathrm{J} \mathrm{Am} \mathrm{Coll}$ Surg. 2019;228(6):861-870.

\section{Disclosures}

The authors report no conflict of interest concerning the materials or methods used in this study or the findings specified in this paper.

\section{Author Contributions}

Conception and design: Schär, Tashi, Beck, Z'Graggen, Raabe. Acquisition of data: Schär, Tashi, Söll, Cipriani, Schwarz. Analysis and interpretation of data: Schär, Tashi, Branca, Z'Graggen, Raabe. Drafting the article: Schär, Tashi, Z'Graggen. Critically revising the article: all authors. Reviewed submitted version of manuscript: all authors. Approved the final version of the manuscript on behalf of all authors: Schär. Statistical analysis: Branca. Administrative/technical/material support: Söll. Study supervision: Z'Graggen, Raabe.

\section{Correspondence}

Ralph T. Schär: Bern University Hospital, University of Bern, Switzerland.ralph.schaer@insel.ch. 